\title{
Cloud optical depth measurements with sun-photometer in Camagüey,
} Cuba

\section{Mediciones de espesor óptico por nubes con fotómetro solar en Camagüey, Cuba}

\author{
Boris Barja $^{(1, *)}$, Yasmine Bennouna(2), Carlos Toledano(2,S), Juan Carlos Antuña(1), \\ Victoria Cachorro(2,S), Carlos Hernández ${ }^{(1)}$, Ángel de Frutos ${ }^{(2, S)}$, René Estevan ${ }^{(1)}$ \\ 1. Grupo de Óptica Atmosférica de Camagüey, Centro Meteorológico de Camagüey, Camagüey, Cuba. \\ 2. Grupo de Óptica Atmosférica. Universidad de Valladolid, Spain. \\ (") Email: bbarja@cmw.insmet.cu \\ S: miembro de SEDOPTICA / SEDOPTICA member \\ Recibido / Received: 13/07/2012. Revisado / Revised: 02/11/2012. Aceptado / Accepted: 03/11/2012. \\ DOI: http://dx.doi.org/10.7149/OPA.45.4.389
}

\begin{abstract}
:
One year of Cloud Optical Depth (COD) measurements obtained with the radiometer (sunphotometer Cimel CE - 318), in Camagüey, Cuba, from June 2010 to May 2011, are presented. As the first step an evaluation method is proposed, in order to confirm that a cloud was measured. This method is based on the complementary cloud information derived from the actinometrical observations. In the second step of the work, the statistical results from the first year of the COD measurements in Camagüey were analyzed. The results show the high quality of COD measurements at Camagüey. The analysis of the COD frequency showed two peaks at the intervals centered in 2.5 and 17.5. Similar behavior occurred each month. The COD mean value for the entire period was 24.8, with a standard deviation of 31.7. The mean monthly minimum and maximum value of COD occurred in December, 2010 and May, 2011, respectively. The diurnal cycle of the mean hourly COD values showed an increase in the afternoon hours. At the same time, the number of measured cases decreased. There was correspondence between the COD data obtained with sun-photometer and CALIOP lidar, for the COD values below 5 . The results showed in this paper constitute the first report of such measurements in Cuba.
\end{abstract}

Key words: Cloud optical depth (COD), Sun-photometer, Camagüey, Cuba.

\section{RESUMEN:}

Se reportan las mediciones de espesor óptico por nubes obtenidas durante un año, desde Junio de 2010 hasta Mayo de 2011, con fotómetro solar en Camagüey, Cuba. Como primer paso se propuso un método de evaluación para confirmar la veracidad de la medición. Este se basa en la información complementaria sobre nubes contenidas en las observaciones actinométricas. En un segundo estado del trabajo, se analizaron los resultados estadísticos del primer año de medición de espesor óptico por nubes en Camagüey. Los resultados mostraron la alta calidad de las mediciones de COD en Camagüey. El análisis de la frecuencia de ocurrencias de COD mostró dos máximos en los intervalos centrados en 2.5 y 17.5. Se observó un comportamiento similar en el análisis de las frecuencias de ocurrencias por meses. El valor medio de COD para todo el período fue 24.8, con una desviación estándar de 31.7. Los valores máximos y mínimos de la media mensual del COD ocurrieron en los meses de Mayo de 2011 y Diciembre de 2010, respectivamente. El ciclo diurno de los valores de la media horaria del COD mostró un incremento en horas de la tarde. Al mismo tiempo el número de casos medidos decreció. Existió correspondencia entre los datos de COD obtenidos con fotómetro solar y lidar en satélite, para valores de COD por debajo de 5. Los resultados mostrados en este trabajo constituyen el primer reporte de este tipo de mediciones en Cuba.

Palabras clave: Espesor óptico por nubes, radiómetro o fotómetro solar, Camagüey, Cuba. 


\section{REFERENCIAS Y ENLACES / REFERENCES AND LINKS}

[1]. G. M. Stokes, S. E. Schwartz, "The atmospheric radiation measurement (ARM) program: Programmatic background and design of the cloud and radiation test bed", Bull. Am. Meteorol. Soc. 75, 1201-1221 (1994).

[2]. A. J. Illingworth, R. J. Hogan, E. J. O'Connor, D. Bouniol, M. E. Brooks, J. Delanoë, P. D. Donovan, J. D. Eastment, N. Gaussiat, J. W. F. Goddard, M. Haeffelin, H. Klein Baltinik, O. A. Krasnov, J. Pelon, J.-M. Piriou, A. Protat, H. W. J. Russchenberg, A. Seifert, A. M. Tompkins, G.-J. van Zadelhoff, F. Vinit, U. Willen, D. R. Wilson, C. L. Wrench, "Continuous evaluation of cloud profiles in seven operational models using ground-based observations”, Bull. Am. Meteorol. Soc. 88, 883-898 (2007).

[3]. B. N. Holben, T. F. Eck, I. Slutsker, D. Tanré, J. P. Buis, A. Setzer, E. F. Vermote, J. A. Reagan, Y. J. Kaufman, T. Nakajima, F. Lavenu, I. Jankowiak, A. Smirnov, "AERONET: A federated instrument network and data archive for aerosol characterization”, Remote Sens. Environ. 66, 1-16 (1998).

[4]. R. Estevan, J. C. Antuña, B. Barja, V. E. Cachorro, A. M. de Frutos, A. Berjón, C. Toledano, B. Torres, R. Rodrigo, T. A. Hernández, C. E. Hernández, "Preliminary results of aerosols measurements with sun photometer at Camagüey, Cuba”, Opt. Pura Apl. 44, 99-106 (2011).

[5]. J. C. Chiu, C.-H. Huang, A. Marshak, I. Slutsker, D. M. Giles, B. N. Holben, Y. Knyazikhin, W. J. Wiscombe, "Cloud optical depth retrievals from the Aerosol Robotic Network (AERONET) cloud mode observations”, J. Geophys. Res. 115, D14202 (2010).

[6]. A. Marshak, Y. Knyazikhin, A. B. Davis, W. J. Wiscombe, P. Pilewskie, "Cloud vegetation interaction: Use of normalized difference cloud index for estimation of cloud optical thickness", Geophys. Res. Lett. 27, 1695-1698 (2000).

[7]. H. W. Barker, A. Marshak, "Inferring optical depth of broken clouds above green vegetation using surface solar radiometric measurements", J. Atmos. Sci. 58, 2989-3006 (2001).

[8]. T. B. Kirilov, Yu. B. Vlasov, M. Ya. Flaum, Manual for Operation and Installation of Solar Radiation Instruments", Ed. Guidrometeoizdat, Leningrad, 124 pp. (in Russian) (1957).

[9]. D. Winker, J. Pelon, J. A. Coakley Jr., S. A. Ackerman, R. J. Charlson, P. R. Colarco, P. Flamant, Q. Fu, R. M. Hoff, C. Kittaka, T. L. Kubar, H. Le Treut, M. P. McCormick, G. Megie, L. Poole, K. Powell, C. Trepte, M. A. Vaughan, V. E. Wielicki, "The CALIPSO mission. A global 3D view of aerosols and clouds", Bull. Amer. Meteorol. Soc. 91, 1211-1229 (2010).

[10]. D. M. Winker, W. H. Hunt, M. J. McGill, "Initial performance assessment of CALIOP”, Geophys. Res. Lett. 34, L19803 (2007).

[11]. M. Vaughan, S. Young, D. Winker, K. Powell, A. Omar, Z. Liu, Y. Hu, C. Hostetler, "Fully automated analysis of space-based lidar data: An overview of the CALIPSO retrieval algorithms and data products", Proc. SPIE 5575, 16-30 (2004).

[12].Z. Liu, R. Kuehn, M. Vaughan, D. Winker, A. Omar, K. Powell, C. Trepte, Y. Hu, C. Hostetler, "The CALIPSO cloud and aerosol discrimination: Version 3 algorithm and test results", 25 th International Laser Radar Conference (ILRC), St. Petersburg, Russia (2010).

[13]. R. Rivero, B. Lapinel, R. Rivero Jr., I. Martínez, J. Morejón, “The atmospheric water vapor content, efficiency of precipitations and the drought in Cuba", Scientific Report in the Cuban National Research Program of Cuba 01301017, 16 pp. (Unpublished Manuscript in Spanish) (1998).

\section{Introduction}

Clouds are a component of the climatic system. They interact with the solar and terrestrial radiation and in turn are essential in the determination of the atmospheric radiation budget. The magnitude of these processes is related with the optical and microphysical properties of the clouds. Thus, the study of the cloud optical properties is very important in order to understand their behavior and their climatic effect. These properties are identified by the optical depth, single scattering albedo, and the asymmetry factor of the cloud drops. Cloud optical depth (COD) is a fundamental value in the determination of the radiative energy balance of the Earth. Nevertheless, this property is very difficult to measure with ground based remote sensing technique using the traditional 
methods. A better representation of the COD in the atmospheric general circulation and climatic models is a challenge in the atmospheric sciences. For those reasons it is necessary to increase the number of COD measurement sites and to improve the accuracy of the measurements.

There are two principal operational networks with the primary objective of the measurements of the cloud characteristics from the ground: the first is of the Atmospheric Radiation Measurement Program (ARM) [1], the second is the network for measurement of clouds (CLOUDNET) [2]. But because of the limited number of measurement sites of these networks it is difficult to obtain a global view of the cloud characteristics.

The Aerosol Robotic Network (AERONET) is designed for the measurements of the optical and microphysical properties of aerosols [3]. AERONET consist of more than 250 measurement sites all over the world with sun radiometers that measure sun direct irradiance and sky radiance. When the cloud is in the instrument field of view the measurement cannot be used for the determination of the aerosol properties. Then it is possible to set the sun-photometer to the 'cloud mode' [3], completing a set of radiance measurements in the zenith to obtain COD values, when no precipitation is present.

A sun-photometer Cimel-318 from the Atmospheric Optics Group (GOA) of the University of Valladolid (Spain) was installed at Camagüey station, in Cuba. This observatory belonging to INSMET (Instituto de Meteorología de Cuba) hosts the GOAC (Grupo de Optica Atmosférica de Camagüey) and the Camagüey station as part of RIMA-AERONET ("Red Ibérica de Medidas fotométricas de Aerosoles" federated to AERONET), within the research official collaboration between GOA and GOAC. Aerosol and cloud measurements with sun-photometer began in October 2008 and June 2010, respectively. The first evaluation about aerosols measurements with sun-photometer was reported for this site by Estevan et al [4].

The objective of the present work is to evaluate in a first approach the potential of the
COD measurements from the sun-photometer and characterize the behavior of COD in one year. The first question to answer is: Does the COD sun-photometer measurements match the actinometric cloud reports? The second is: How was the behavior of the COD during the first year of measurements in Camagüey? Complementary cloud information reported hourly by actinometric measurements was used in the validation while the validated sun-photometer COD data and satellite measurements were used to answer the second question.

\section{Instrument and methods}

A sun-photometer Cimel CE-318 was installed in Camagüey $\left(21.42^{\circ} \mathrm{N}, 77.84^{\circ} \mathrm{W}, 128 \mathrm{~m}\right.$ asl), Cuba as part of the RIMA-AERONET network, providing the data used in the present work. The sun-photometer acquires sun direct irradiance and sky radiance with a field of view of $1.2^{\circ}$ in the wavelengths of $340 \mathrm{~nm}, 380 \mathrm{~nm}, 440 \mathrm{~nm}$, $500 \mathrm{~nm}, 675 \mathrm{~nm}, 870 \mathrm{~nm}, 936 \mathrm{~nm}$ and $1020 \mathrm{~nm}$ [3].

In the case that a cloud is in the instrument field of view, the measurement is discarded when determining the aerosol properties. It was proposed recently by Chiu et al [5], that under such conditions ten radiance measurements toward the zenith will be conducted in each wavelength channel. This mode of the instrument operation is named 'cloud mode'. It is based on the suggestion of the use of two wavelength measurements at red and near infrared wavelengths to retrieve COD values over vegetation $[6,7]$.

The method for the COD determination deployed in AERONET was explained in detail by Chiu et al [5]. Nevertheless some points are given here. There is no one to one relationship between zenith radiances and COD. So, two wavelengths radiance measurements $(470 \mathrm{~nm}$ and $870 \mathrm{~nm}$ ) are used to reduce the ambiguity. Combining the radiance in these two wavelengths, radiative transfer calculations, and satellite data the COD value is obtained [5]. The reported COD value is the average of the 10 instantaneous values. The dataset used in the present study spans from June 2010 to May 2011, with 2276 COD values. 
An algorithm was proposed to evaluate the COD measurements. This approach aims to determining the 'correct' COD values. The reports of clouds in the hourly actinometric observations were used as reference. The term 'correct' must be understood in two senses: first, there was a cloud and therefore the decision of the radiometer to make the COD measurement was correct; and second, this COD value is related with cloud type information in the actinometric report.

The parameters of the actinometric information about cloudiness used in the algorithm were: the solar disk state (SDS), sky fraction covered by clouds (SFT), sky fraction covered by low cloud types (SFL), atmospheric phenomena occurring at the time of observation (PHEN), cloud types present in the sky (CLDT), cloud types present in the zenith direction (CLDZ) [8]. The factors PHEN, CLDT, CLDZ and SDS are described in Table I. The covered sky fractions are evaluated on the base of tenth parts.

Table I

Parameter codification for atmospheric phenomena (PHEN), cloud types (CLDT and CLDZ) and solar disk state SDS.

\begin{tabular}{|c|c|c|c|}
\hline PHEN & Description & CLDT & Description \\
\hline 0 & Not present & 0 & Not present \\
\hline 1 & Dew & 1 & Cumulus (Cu) \\
\hline 2 & Haze & 2 & $\begin{array}{l}\text { Stratocumulus } \\
\text { (Sc) }\end{array}$ \\
\hline 3 & Fog & 3 & Stratus (St) \\
\hline 4 & Mist & 4 & $\begin{array}{l}\text { Cumulonimbus } \\
\text { (Cb) }\end{array}$ \\
\hline 5 & $\begin{array}{l}\text { Heavy } \\
\text { shower }\end{array}$ & 5 & Altocumulus (Ac) \\
\hline 6 & Rain & 6 & Altostratus (As) \\
\hline 7 & $\begin{array}{l}\text { Storm with } \\
\text { precipitation }\end{array}$ & 7 & Nimbostratus (Ns) \\
\hline 8 & $\begin{array}{l}\text { Storm } \\
\text { without } \\
\text { precipitation }\end{array}$ & 8 & Cirrus (Ci) \\
\hline 9 & Smoke & 9 & Cirrostratus (Cs) \\
\hline & & 10 & Cirrocumulus (Cc) \\
\hline SDS & \multicolumn{3}{|l|}{ Description } \\
\hline 0 & \multicolumn{3}{|l|}{ Clear solar disk } \\
\hline 1 & \multicolumn{3}{|c|}{$\begin{array}{l}\text { Solar disk can be seen through the cloud } \\
\text { with clear defined outline }\end{array}$} \\
\hline 2 & \multicolumn{3}{|c|}{$\begin{array}{l}\text { Solar disk can be seen through the cloud } \\
\text { with unclear defined outline }\end{array}$} \\
\hline 3 & \multicolumn{3}{|c|}{$\begin{array}{l}\text { Solar disk cannot be seen through the } \\
\text { cloud }\end{array}$} \\
\hline 4 & \multicolumn{3}{|c|}{ Solar disk is obstructed by an object } \\
\hline
\end{tabular}

The steps of the used algorithm are described below:

1. Evaluate the direct coincidence between actinometric report and COD measurement, as given by less than 10 minutes difference $(\Delta t)$ among them.

2. If the first step is satisfied the cloudiness characteristics are evaluated.

2.1. If SDS value is higher than 1 , the sunphotometer can enter in the 'cloud mode'. But it does not mean that there are clouds in the zenith. Thus it is necessary to evaluate the SFT, SFL, CLDT and CLDZ.

2.1.1. If SFT is between 1 and 3 and the COD measurement time is between 15:00 GMT and 19:00 GMT (10:00 LT and 14:00 LT (GMT -05:00)), the COD measurement is selected as 'correct'.

2.1.2. If SFT is between 4 and 10 and the SFL is equal to SFT, the COD is selected as 'correct'.

2.2. Always the COD values are compared with CLDT and CLDZ to evaluate the correspondence. Values of COD (below 10) are related with thin, high clouds or thin low clouds (e.g. $\mathrm{Ci}, \mathrm{Cc}, \mathrm{Cs}, \mathrm{Cu}$ ); middle range values of COD $(\sim 10$ up to 30) are associated with medium thick clouds in all levels; and high COD values $(>30)$ are associated with thick clouds in all levels.

3. If the first step is not satisfied, it is necessary to compare cloudiness characteristics from the actinometric observations before and after the COD measurement time.

3.1. If the cloudiness characteristics that indicate the presence of cloud (SFT $>5$, CLDZ $>0$, SFL $>4$, PHEN $>4$, CLDT $\sim$ COD) are similar in both actinometric observations, the COD is selected as 'correct'.

3.2. CLDT and CLDZ are compared in both actinometric observations to evaluate the COD value with the limits shown in the point 2.2.

A set of COD values was obtained with the COD selected as 'correct'. The features of this COD dataset were analyzed for the complete period from June 2010 to May 2011, as well as in monthly and hourly basis. 
The COD values from Cloud-Aerosol LIdar with Orthogonal Polarization (CALIOP) level 2 cloud and aerosol products, version 3.01, were used to compare the values to the sunphotometer data. CALIOP is the primary instrument on the Cloud-Aerosol Lidar and Infrared Pathfinder Satellite Observations (CALIPSO), launched in April 2006 [9]. This instrument is used to characterize the vertical distribution of cloud and aerosols. CALIOP operates at two wavelengths, $532 \mathrm{~nm}$ and 1064 nm. Details on the instrument design and performance are described [10]. Detection of cloud layers primarily relies on the $532 \mathrm{~nm}$ channel. Cloud layers are detected using an adaptive threshold detection technique applied to profiles of attenuated scattering ratio [11]. There is an algorithm to cloud and aerosol discrimination (CAD), to calculate the cloud optical depth. The CAD algorithm is a fivedimensional probability density function (PDF) based approach [12]. The CALIOP maximum COD value is $\sim 5$, due the total laser energy extinction by thicker clouds.

A set of COD values from CALIOP in the same year interval was selected. The areal window selected was $1 \times 1$ degree centered at the measurement site location $\left(21.42^{\circ} \mathrm{N}, 77.84^{\circ} \mathrm{W}\right)$.

\section{Results and discussion}

The set of original COD measurements in the period consisted of 2276 values. After applying the evaluation algorithm 2249 COD values were selected as 'correct', representing the $98.8 \%$ of the cases. Only 25 cases were rejected and 2 cases could not be compared because no actinometric measurements were available. The rejected cases were related with low values of COD and the absence of cloud in the zenith. In general thus results showed the good agreement between the sun-photometer COD measurements and the actinometric reports of clouds.

COD frequency distribution is shown in Fig. 1, with an interval of 5 units of COD. The maximum frequency of $17.3 \%$ was found in the interval centered at 2.5. The COD frequency values increased from COD values centered in 7.5 to the secondary maximum at the interval centered in
17.5. Then the frequency values decreased for higher values of COD. Finally, the interval centered in 97.5 had an increase to $3.1 \%$. The mean value of COD was 24.8 with a standard deviation of 31.7. This result shows a similar frequency distribution as the report by Chiu et al [5] for three years of data from November, 2004 to June, 2008 at the ARM measurement site of Oklahoma, USA. The authors discarded the extreme values of COD, values lower than 3 and higher than 90, from the dataset, with the objective of comparing the data [5]. For the measurements in Oklahoma the authors showed a maximum frequency of $24 \%$ at COD value near to 23. The results for Camagüey and Oklahoma sites showed similar behavior of the COD, but on a different magnitude. The data sets for both sites showed some differences, because of the different extension of the datasets and different geographical location.

The frequency distributions of all months are shown in Annex A. The shapes of the distributions were similar. Some months showed the secondary maximum in the interval centered at 12.5 or 22.5 . In other months the primary maximum at 2.5 changed to a secondary maximum. April 2010 showed a particular behavior, with a more flat distribution. A primary maximum stayed in the interval centered in 2.5 , but the other intervals centered from 12.5 to 47.5 showed similar values with a slow decrease (Annex A).

Figure 2 shows the behavior of the monthly mean COD values and the number of cases in each month for the measurement period. The

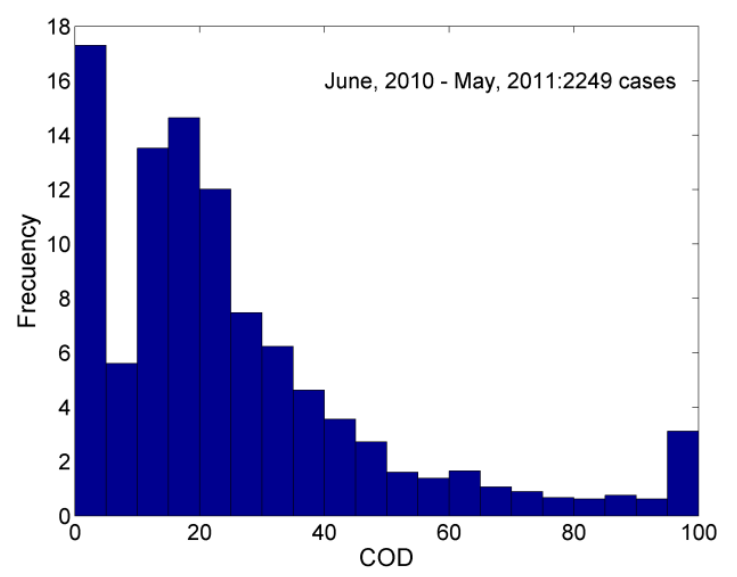

Fig. 1. COD frequency distribution for the period from June 2010 to May 2011, in Camagüey. 


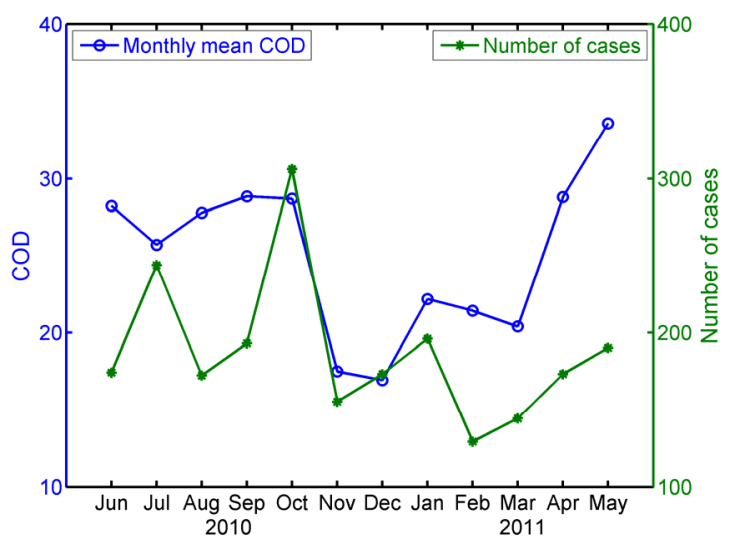

Fig. 2. COD Monthly means for the period from June 2010 to May 2011.

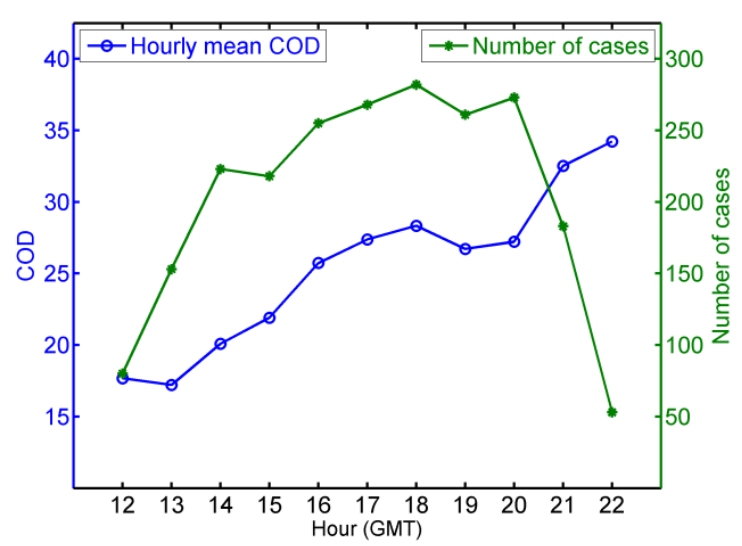

Fig. 3. COD Hourly means for the period from June 2010 to May 2011.

COD monthly mean maximum value of 33.6 was in the month of May 2011. The minimum value of COD was 16.9 in December 2010. The number of cases reached their maximum of 306 and minimum of 129 in October, 2010 and February, 2011, respectively. This result reflected the seasonal synoptical pattern at the measurement site. There are two seasons, rainy (May to October) and little rainy (November to April). The COD values presented in figure 2 showed a subdivision by season. COD values smaller than 23 in the months from November 2010 to March 2011 corresponded to the little rainy season. COD values higher than 25 in the rest of the months corresponded to the rainy season. Note that it is the number of cases of nonprecipitation clouds. The extreme values of the number of cases, with minimum in February and maximum in October, are associated with the clouds seasonal synoptical pattern at the measurement site. But there were other maximums corresponding to the months of July and January. Also there were other minimum values reached in November and August months. These maximums and minimums were reached in months corresponding to both seasons. The minimum in August and low value in September was produced due to rain. These months correspond to the rainy period, where there are many clouds and they just could not be measured because of the frequent occurrence of storm and rain. In the rainy period there is a dry sub-period with a reduction of the rain amount [13]. July was a month in this sub-period, and the maximum value was related with this phenomenon. In October the reduced amount of the storms and rain increased the number of non-precipitation clouds.

The mean COD daily behavior is shown in Fig. 3 . The COD hourly mean values increase with the hour during the day. The maximum value of the COD hourly mean value was 34.2 at 22 GMT; the minimum value of 17.2 was at 13 GMT. There was a slowly decrease in the hours 19 GMT and 20 GMT, in the middle-afternoon. In the transition to the 21 GMT there was an increase in the mean hourly COD value, to reach the maximum in the day. This result was associated with the development of the cloudiness during the day. A maximum COD value was reached at the 22 GMT, when the precipitating clouds reach their maximum development. In the months of the rainy period there were more frequent higher values of COD at 22 GMT hours (not shown). The number of cases had a maximum of 282 at 18 GMT. The minimum number of cases was observed at 22 GMT. In September and October there were no cloud measurements with the sun-photometer at that time, because of the presence of rain. At the 21 GMT and 22 GMT the COD values had their maximum and the numbers of cases had lowest values. At this time there were fewer non-precipitation clouds, but they were optically denser clouds.

CALIOP is able to detect clouds with COD $\leq 5$. The total number of cases measured with CALIOP inside the selected geographical boundaries was 271. For the COD values below 5 measured with sun-photometer, the total 

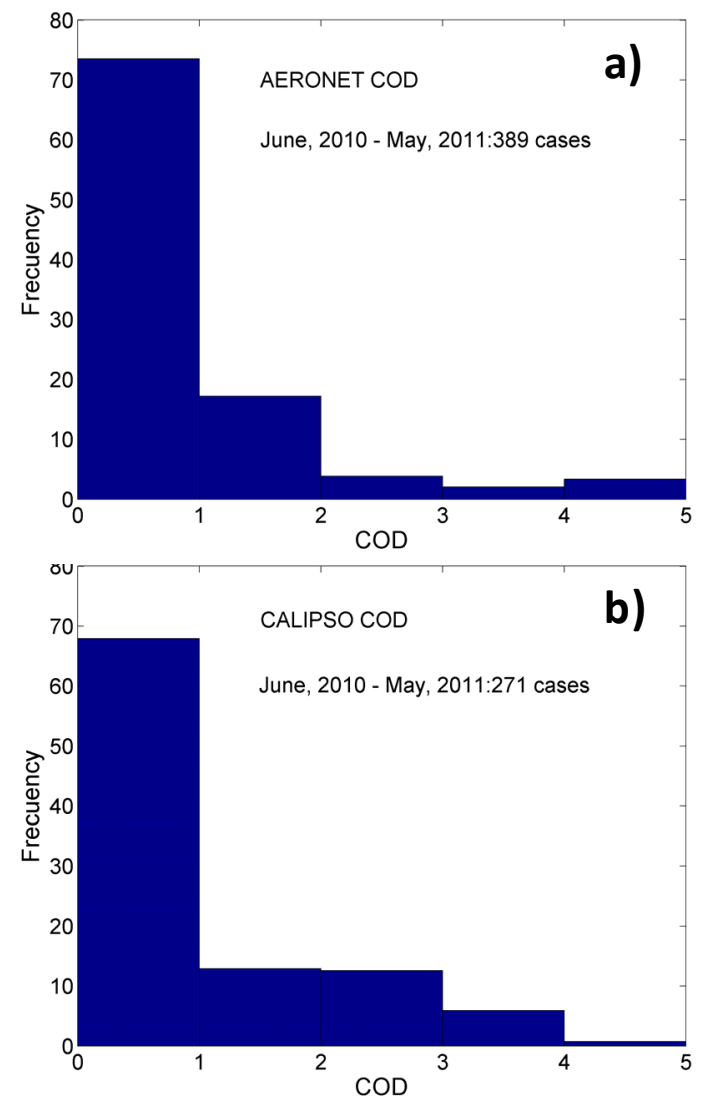

Fig. 4. COD frequency distribution for the period from June 2010 to May 2011, in Camagüey, for the values below 5, a) with sun-photometer, AERONET, b) with lidar CALIOP onboard CALIPSO.

number of cases was 389. Figure 4 shows the frequency of distribution of the COD values below 5 for both instruments with an interval of 1 unit of COD. The distribution was similar for COD data from both instruments. Maximum frequency of occurrence was in the interval centered in 0.5 for both instruments, with values of $73.5 \%$ and $67.9 \%$ for AERONET and CALIPSO, respectively. The frequency of occurrence decreased with an increase of COD values. Mean (standard deviation) values of COD was 0.80 (0.96) and 0.92 (1.07) for AERONET and CALIPSO data, respectively.

\section{Conclussions}

This is the first report on cloud optical depth obtained with radiometer in Cuba, complementing former aerosols optical depths studies at the same site. The COD frequency distribution showed maxima at the intervals centered in 2.5 and 17.5. The frequency distribution of COD agreed with other reports. There was a monthly COD maximum of 34.2 in May 2011. The maximum value of the number of cases occurred in October. Monthly and hourly mean values of COD showed the concordance with the natural behavior of the clouds in our region. There was good agreement between the COD values below 5 measured with CALIPSO and AERONET, in the studied period.

\section{Acknowledgements}

Authors from GOAC-INSMET want to thank to GOA-UVA team by the support and logistic. To AERONET NASA our gratitude for including Camagüey site on the AERONET web site. This work has been supported by the Cuban National Climate Change Research Program under the contract number 01301204 and by the Collaboration Agreement between the Grupo de Óptica Atmosférica (GOA-UVA) and the Grupo de Óptica Atmosférica de Camagüey (GOACINSMET). Financial support from GOA-UVA was provided by: the Spanish CICYT (CGL200805939-C03-01/CLI, CGL2009-09740 and CGL2010-09480-E; CGL2011-13085-E). 


\section{Annex A}
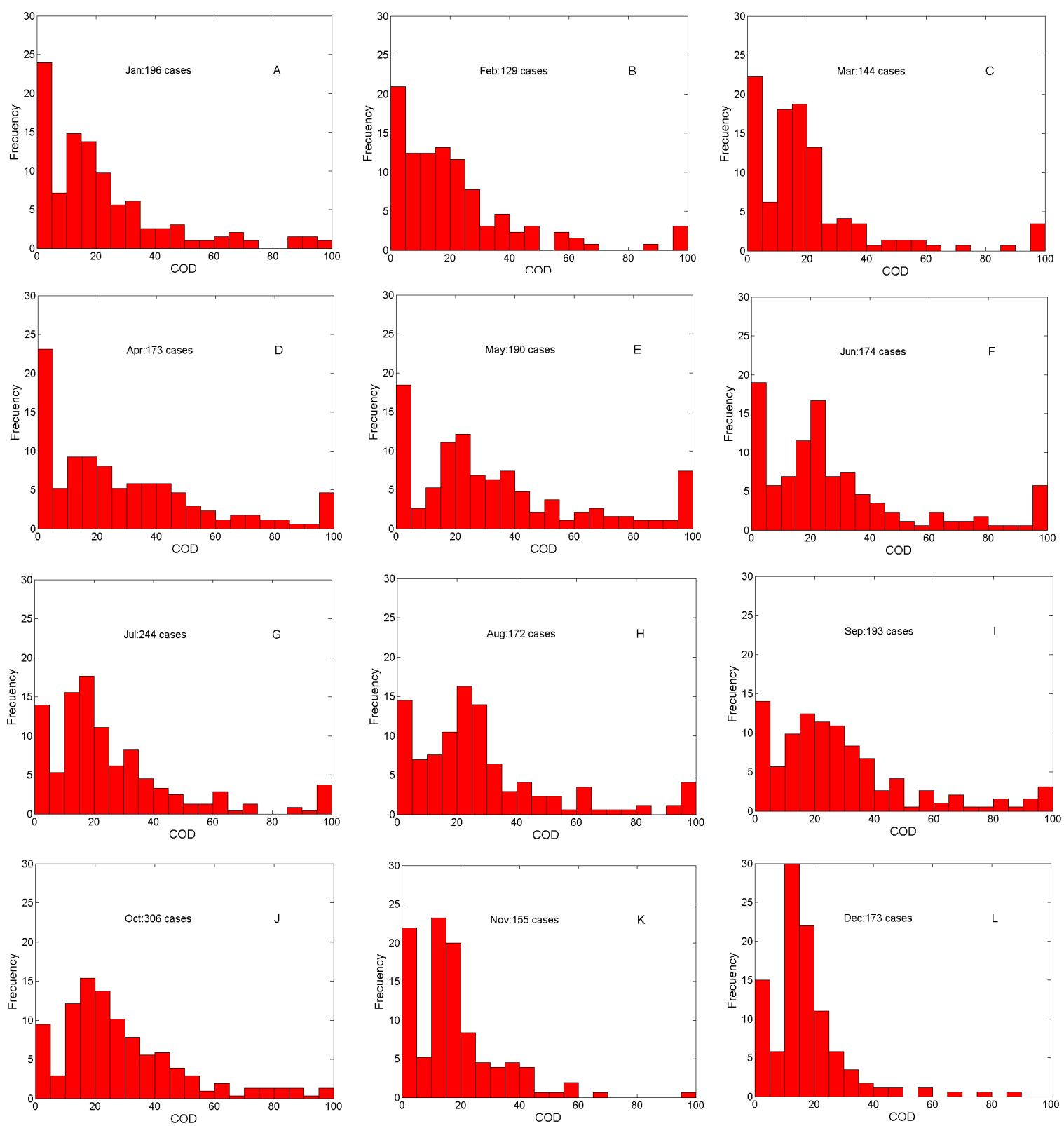

Fig A1. COD frequency distribution for each month in the period from June 2010 to May 2011, in Camagüey obtained with sunphotometer. 